\title{
A universidade, a educação social e a formação do socieducador*
}

The university, social education and the education of social educator

\section{Resumo:}

O artigo discute as relações entre a universidade e a socioeducação e seus desdobramentos na formação do socioeducador com apoio na concepção de uma educação vinculada aos direitos coletivos. Destaca as relações entre teoria e as ações da educação social, a formação continuada do socioeducador, a partir de três eixos: aspectos do ensino superior no Brasil, o chamamento à educação de caráter mais geral frente às demandas decorrentes do contexto contemporâneo, no qual a educação formal, em seus diferentes níveis, não consegue atender às solicitações de crianças, jovens e adultos das camadas populares e, ainda, os requerimentos necessários à formação continuada do socioeducador. As leituras mostraram que o debate é insuficiente diante das experiências de socioeducação realizadas nos cenários internacional e nacional. Há um campo a ser efetivamente constituído.
\end{abstract}

Irandi Pereira*

Rosa Elisa Mirra Barone***

Palavras-chave: Universidade. Educação social. Formação do socioeducador.

\begin{abstract}
:
This article discusses the relations between university and social education and their developments in the social educator education supported by an education conception linked to the collective rights. This article emphasizes the relations between theory and the social education actions, the social educator continual education, according to three focus: Brazilian higher education aspects, the call for a more general education towards the demands resulting from the contemporary context, in which the formal education, in its different levels, cannot answer the low income adults, youngsters and children solicitations and yet the requests needed for the social educator continual education. The readings have shown that the debate is insufficient in face of the social education experiences carried out in national and international scenarios. It is a field to be effectively established.
\end{abstract}

Keywords: University. Social education. Social educator education.

\section{Introdução}

\footnotetext{
* Artigo apresentado no III Congresso Ibero Americano de Política e Administração da Educação/Zaragoza/Espanha, novembro de 2012.

** Doutora em Educação - USP; docente e coordenadora do Mestrado Profissional Adolescente em Conflito com a Lei da Universidade Bandeirante/Anhanguera - São Paulo. irandip@gmail.com

*** Doutora em Educação - PUC-SP; docente no Mestrado Profissional Adolescente em Conflito com a Lei da Universidade Bandeirante/Anhanguera São Paulo. rebarone@uol.com.br
} 
Este artigo tem como proposta discutir as relações entre a universidade e a socioeducação e seus desdobramentos na formação do socioeducador. Os pressupostos dessa discussão residem na concepção de uma educação vinculada aos direitos coletivos e seu compromisso na emancipação de cada um como sujeitos históricos. A socioeducação contempla esse ideário avançando na compreensão das questões da educação enquanto afirmação e efetivação dos direitos humanos e na perspectiva do direito coletivo (ARROYO, 2007). Esses são elementos que orientam proposições da educação social, fundadas no compromisso com a emancipação e autonomia das camadas populares, forjando "suas práticas educativas em atos, atitudes e gestos que fazem uso da ética, da indignação, da esperança e do ideal de liberdade" (BAPTISTA, 2007, p. 86). Nesse contexto, o socioeducador tem sua ação profissional diversificada e interdisciplinar e está presente em diferentes cenários socioinstitucionais de formação, apoio e desenvolvimento pessoal e social que considere os direitos básicos com a vida, saúde, a convivência familiar e comunitária, a educação escolar dentre outros.

A análise dessa temática tem como ponto de partida o cenário socioprodutivo, e seus desdobramentos, desenhado no final da década de 1980 e, sobretudo, na virada de século, fortemente influenciado por questões como a globalização da economia, a mundialização, a revolução informacional, pelos impactos dessas mudanças no mundo do trabalho, bem como nas relações entre público e privado, esse quadro esta presente na conformação das políticas públicas e, por suposto, nas reflexões que têm como eixo as relações entre educação e sociedade. Ao mesmo tempo, e decorrente dessas mudanças de caráter global, observa-se a imposição de uma cultura do individualismo explicitada em valores e princípios, que estão presentes no âmbito familiar, escolar e social.

Outro aspecto que está presente nesse cenário refere-se à cultura de direitos humanos que, em sua versão moderna, nasce no século XVIII, cujos protocolos históricos e internacionais ${ }^{1}$ valorizam cada indivíduo como portador de direitos naturais e como cidadão, o que significa o reconhecimento da singularidade de cada ser humano - sua liberdade e sua autonomia - independentemente de sua classe social, cor, gênero, religião ou nacionalidade.

\footnotetext{
${ }^{1}$ A Declaração de Independência Norte-Americana (1776), a Declaração dos Direitos do Homem e do Cidadão (1789) e a Declaração Universal dos Direitos Humanos (1948).
} 
O debate sobre a universidade e sua relação com a socioeducação, compreendendo a teoria e as ações originárias da educação social e, ainda, a formação continuada do socioeducador contempla três eixos que são complementares. Um deles diz respeito aos elementos que caracterizam historicamente a trajetória do ensino superior no Brasil. Outro diz respeito ao chamamento à educação de caráter mais geral frente às demandas decorrentes desse novo cenário socioprodutivo no qual a educação formal, em seus diferentes níveis, não consegue atender às solicitações de crianças, jovens e adultos das camadas populares, no ambiente escolar. Estudos sobre essa questão têm apontado para a existência de uma convivência difícil entre esses sujeitos e a sociedade em que vivem, não são respeitados ou ouvidos, sobretudo no interior do sistema escolar. Nesse quadro, as alternativas tendem a se tornarem cada vez mais individualizadas, o que propicia a difusão de uma "cultura da violência" ${ }^{2}$ fomentada por uma ordem social excludente (ESPINHEIRA, 2003). Nesse cenário em que a banalização da violência e o desrespeito aos direitos humanos têm ocupado grande espaço na agenda pública, a educação social e as ações da socioeducação dela decorrentes podem contribuir para mudanças nas relações sociais e, sobretudo, na formação do socioeducador.

Em estudos sobre o ensino superior Cury (2004, p. 791) destaca que "a graduação tem como conceito regulador o princípio da preservação enriquecida, cujo ensino se volta para uma profissionalização, compromissada e competente, necessária à inserção profissional no mundo atual". Contudo, Arroyo ${ }^{3}$ aponta para a necessidade de uma reflexão sobre a pertinência das tradicionais concepções de educação em "tempo de barbárie", recupera outra concepção de educação (educação social) diferente daquelas velhas concepções de ensinar e formar, entendendo que neste quadro de desconstrução de direitos e de sujeitos humanos a dimensão com o cuidado, com a proteção à pessoa, deve se constituir em direito. Significa dizer que "recuperada a dimensão que nunca a educação assumiu que o cuidar também é educar, que proteger também é educar" (ARROYO, 2007,

\footnotetext{
2 "A grande maioria dos que morrem vítimas de violência tem entre 15 e 24 anos, ou 15 e 29 anos. Dependendo da forma de fazer as contas. São, em geral, pobres, do sexo masculino, moram nos bairros menos valorizados e, frequentemente, são negros" (SOARES, 2011, p. 19). Pesquisa recente mostra que homicídio de jovens com até 19 anos cresceu 376\% desde 1980 no Brasil, e 259\% foi a variação do número de homicídios de pessoas de todas as idades. A pesquisa considerou o período entre 1980 e 2010. Waiselfisz, Julio Jacobo Waiselfisz. Mapa da Violência 2012 - Crianças e adolescentes do Brasil. In: Folha de São Paulo, Caderno C5, 18 de junho de 2012.

3 Ibidem.
} 
p. 187). Essa discussão está presente no terceiro eixo deste artigo que apresenta aspectos sobre a educação social e a formação do socioeducador.

Ademais, essa temática não ocupa ainda o seu devido lugar nos diferentes espaços da academia e, em especial, nas implicações do conhecimento produzido e sua extensão no cotidiano da vida social.

\section{Elementos que caracterizam historicamente a trajetória do Ensino Superior no}

\section{Brasil}

Uma breve incursão na história da educação superior e a identificação de alguns marcos significativos de sua trajetória estão presentes na atual configuração da universidade brasileira. É importante destacar que o país ainda carece de um modelo próprio de universidade, valendo-se sempre de exemplos e de experiências de países centrais. Os estudos mostram a existência de uma superposição de modelos entre as instituições de ensino superior (IES) em âmbito público e privado.

Desde o seu advento, a educação superior, no país, esteve voltada para os filhos das famílias da elite social e econômica. No Brasil Colônia, os jovens eram enviados para estudar nas universidades europeias, especialmente, em Coimbra, Portugal. Por volta de 1808, com a chegada da Corte portuguesa, registra-se a criação das primeiras escolas isoladas de educação superior, no país, concebidas à luz do "modelo napoleônico", centrado em cursos e faculdades, estruturados de forma independente e não propriamente a partir da concepção de universidade. O "modelo", centralizado do ponto de vista administrativo, mas dissociado em relação à integração das faculdades, via no ensino superior um importante mecanismo para formar os profissionais necessários ao funcionamento da sociedade e, ao mesmo tempo, um importante instrumento para disseminar as doutrinas vigentes (TRINDADE, 1998). Esses cursos e faculdades se destinavam principalmente à formação dos quadros necessários à burocracia do Estado, em consonância com as suas doutrinas.

Vale destacar que o Brasil esteve fora do debate sobre um novo projeto de universidade empreendido por países europeus, posto que somente em 1920, portanto, bastante tardiamente (CUNHA, 2007), é criada a Universidade do Rio de Janeiro, a primeira universidade do Brasil, fruto de uma confederação de escolas (FÁVERO, 1999). Alguns anos 
mais tarde, em 1927 é inaugurada a Universidade Federal de Minas Gerais, à luz do modelo neonapoleônico, aglutinando cinco faculdades. Os cursos propostos, concebidos sob a ótica da ciência positivista, delimitava rigidamente os campos de conhecimento. Esse modelo, de inspiração napoleônica, influencia as universidades brasileiras tanto em relação à oferta de cursos e programas, quanto ao não incentivo ao desenvolvimento de processos divergentes de pensamento.

No contexto da Revolução de 1930, são registrados dois projetos de universidade com propostas assemelhadas: o da Universidade de São Paulo (USP), em 1934, e o da Universidade do Distrito Federal (UDF), em 1935. Em que pese, na UDF, as ideias liberaisprogressistas de seus mentores quanto à criação de uma instituição autônoma, responsável pela produção do "saber desinteressado" e pela formação de indivíduos críticos e "cultores da liberdade", a proposta não se consolida em razão de pressões de segmentos conservadores da sociedade. Na USP, é criada a Faculdade de Filosofia, Ciências e Letras (FFLCH) como um "centro integrado de busca e de crítica do saber", sob a inspiração do modelo germânico humboldtiano, pautado na concepção da indivisibilidade entre o saber, o ensino e a pesquisa (TRINDADE, 1998).

A proposta sofre oposição das demais instituições superiores de formação profissional cuja autonomia, estrutura, mentalidade e tipo de ensino certamente sofreriam limitações sob essa nova concepção de universidade. Por quase três décadas, de 1934 a 1959, a FFLCH resiste às pressões tal qual "um Estado dentro do Estado", mas, desprovida de poder político, a proposta acaba por se descaracterizar. Nessas condições, a Universidade paulista sobrevive como uma federação de escolas, incorporando, pois, traços do modelo napoleônico profissional (SGUISSARDI, 2004).

No início dos anos 1960, as várias correntes da intelectualidade brasileira e os estudantes discutem uma nova proposta de universidade para o país em meio a um crescimento espontâneo e desordenado das IES. Em 1962, é fundada a Universidade de Brasília (UnB) que, considerada um "projeto coletivo da intelectualidade brasileira", reacende a ideia de um modelo de universidade baseado na associação do ensino e da pesquisa e de uma estrutura integrada por meio da coordenação das atividades das várias unidades de ensino. Vista como uma inovação face ao modelo tradicional baseado em 
faculdades e escolas independentes e consideradas autossuficientes, a experiência da UnB foi logo abortada pelo golpe militar de 1964 (CUNHA, 2007).

Ainda, no início da década de 1960, o movimento dos estudantes liderado pela União Nacional dos Estudantes (UNE) defendia uma reforma universitária como parte das Reformas de Bases defendidas pelos setores progressistas do país. Uma das principais bandeiras de luta dos estudantes era a democratização da universidade, traduzida principalmente pela democratização do acesso ao ensino superior, o que deveria ocorrer pela ampliação do número de vagas, pela rediscussão dos exames vestibulares, entre outros aspectos (SGUISSARDI, 2004).

Em 1968, o governo militar implanta a Reforma Universitária por meio da Lei no 5.540, sob inspiração do acordo entre o Ministério da Educação e Cultura (MEC) e a United States Agency for International Development (USAID), que impunha diretrizes à produção do conhecimento e ao processo de pesquisa a serem realizados pelas universidades brasileiras. A legislação da ditadura militar rompe com o modelo neo-humboldtiano na medida em que a responsabilidade pelo desenvolvimento de pesquisas passa a ser da pósgraduação, enquanto que à graduação caberia a formação dos quadros de profissionais especializados para atender às demandas do "modelo" econômico então denominado de milagre brasileiro. Com foco no mercado e a cisão entre ensino e pesquisa, no âmbito da graduação e da pós-graduação, que leva a uma quase estagnação do processo de criticidade no âmbito dos cursos de graduação, a Reforma resgata o caráter arcaico do modelo napoleônico (ANASTASIOU, 2001).

A partir de meados dos anos 1990, a legislação federal por meio dos Decretos $n^{\circ}$ 2207, n 2306 de 1997 e n 3.860 de 2001, concebidos sob inspiração neoliberal e influência efetiva do Banco Mundial, estabelece que a indissociabilidade entre ensino, pesquisa e extensão se aplica apenas às universidades. Deixam desobrigadas as IES, contrariando o artigo 207 da Constituição da República Federativa do Brasil, que estabelece o vínculo entre as três instâncias. Tal situação dá indícios da existência de uma superposição ou dualidade de modelos de universidades (SGUISSARDI, 2004).

Trindade (1998) chama a atenção para a crise da universidade que, para além do público e do privado, é a crise da instituição na atual sociedade do conhecimento, cuja ênfase é dada à formação de profissionais polivalentes para o mercado. O autor destaca 
também o modelo emergente de universidade "pública" e privada, que denomina de neoprofissional e competitivo.

A despeito dos modelos de universidade encontrados no cenário brasileiro, é importante destacar que a educação superior continua sendo um segmento educacional voltado a uma minoria. Dados recentes mostram que apenas $10 \%$ da população com idade superior a 24 anos tinham esse nível de ensino.

Em síntese, ao considerar que o ensino superior e, por suposto, a universidade foram criados para formar uma elite aristocrática e, posteriormente, uma elite de mérito, como quaisquer outras instituições, precisam dar respostas aos processos de desenvolvimento econômico e social. As mudanças em curso no cenário socioprodutivo e as questões sociais advindas dessas mudanças demandam por produção de conhecimento e por profissionais comprometidos nos processos de transformação social, pautados nos direitos humanos. Mais que isso, demanda sair do isolamento, do alheamento e do corporativismo que em geral conduzem à inércia acadêmica e ao descompromisso com a sociedade que a mantém (MOISEICHYK; BIAZÚS, 2001). Como destacado pelos autores, essa postura de olhar o contexto no qual se insere

[...] deve permear a atividade-fim das universidades, culminando com uma proposta pedagógica que tenha, como eixo central, a formação de profissionais-cidadãos, e com uma visão de universidade que, sem descuidar do desenvolvimento científico e tecnológico, esteja alerta e atenta às necessidades mais prementes do seu contexto social (MOISEICHYK; BIAZÚS, p. ,2001).

A reflexão sobre o papel das universidades na sua relação com a sociedade deve, portanto, contar com novas ações e práticas que conduzam à compreensão de que a questão social contemporânea pode ser enfrentada pelos caminhos da ciência, e isto está apenas começando (MOISEICHYK; BIAZÚS, 2001).

\section{A universidade e a educação social}

Diferentes são os estudos que demonstram que outras instâncias fora do circuito institucionalizado, a exemplo da escola e do trabalho, passaram a concorrer para a socialização e processos de inserção dos segmentos mais vulneráveis da população nos 
espaços urbano e rural, inclusive bairros periféricos, com destaque para as redes de solidariedade e de sociabilidade que são tecidas pelos sujeitos individuais e coletivos.

A educação social está presente nas ações da socioeducação enquanto fundamentos teóricos, nos conteúdos e nas metodologias requeridas para o socioeducador atuar em uma sociedade marcada por processos de dominação e exclusão, nos diferentes contextos. Como assinalado por Ribeiro (2006, p. 160), o próprio conceito de

[...] educação social está indissociavelmente vinculado ao de exclusão [...]. É como uma resposta afirmativa e adequada que a educação social emerge no debate sobre: Que educação oferecer aos milhares de crianças, adolescentes e adultos excluídos da e na escola; do e no emprego; da e na terra; das e nas instituições sociais? Seriam os educadores formados por instituições regulares de ensino, dentro dos princípios, objetivos, conteúdos e métodos tradicionalmente direcionados aos incluídos, os mais preparados para educar os que experimentam as situações de exclusão social?

A educação social caracteriza-se como um novo campo profissional que, embora articulada com a Pedagogia, a Sociologia, a Psicologia e a Assistência Social dentre outros, tem características próprias e mais específicas que o espaço propiciado aos profissionais desses campos do conhecimento, apresentando caráter multi e interdisciplinar, devendo ser analisada a partir das relações entre educação e demandas sociais.

A literatura sobre a educação social, ainda que limitada, mostra diferentes eixos no debate e, em especial, como sinônimo da pedagogia social, aspecto que tem provocado inúmeros questionamentos. Em outros momentos, há indagações sobre sua inserção no campo da educação não formal.

No cenário internacional, com destaque para o europeu, ${ }^{4}$ a formação de educadores sociais está presente há muitos anos. Estudo realizado por Machado (2009) mostra a presença desse campo de formação em diferentes países, com ênfase na diversidade que ocorre em relação à denominação do profissional, na duração dos cursos, nas áreas de intervenção e na regulamentação.

\footnotetext{
4 Cabe destacar que a proposição da educação social pelos diferentes países da Europa pode ser compreendida como uma das respostas educativas aos desafios sociais, econômicos e culturais decorrentes das políticas do Estado de Bem-Estar Social. Ao mesmo tempo, os cursos oferecidos relacionados estão em conformidade com as determinações do Processo de Bologna.
} 
A denominação pedagogia social, formando o pedagogo social, ocorre em países como Alemanha, Dinamarca e Países Baixos, com cursos focados na assistência sociopedagógica. Outros países utilizam a denominação educação social e forma, como na Bélgica, o educador-guia em curso que integra, desde 1996, a área pedagógico-sanitária e socioeducativa. França e Espanha, na mesma linha, formam o educador social e o educador especializado, respectivamente. Destaca-se que, na França, as discussões focalizam os problemas sociocomunitários e as questões da terceira idade. Na Irlanda, o educador social, com diploma interno e reconhecido em curso de três anos, tem como eixo a atuação junto aos jovens em conflito com a lei, saúde, crianças e adolescentes com dificuldade social.

Com características um pouco diferentes, a Finlândia oferece o Diploma de Serviços Sociais sem qualificação específica. Situação semelhante ocorre na Grécia com a recente criação de um curso voltado para as questões sociocomunitárias, mas sem denominação oficial.

Outros países utilizam o termo educador profissional para os que atuam nas situações e contextos socioeducativos e comunitários. Nesse grupo, encontra-se a Itália, que promove uma formação articulando diferentes escolas superiores e tem como foco estudos sobre crianças, adolescentes, jovens, adultos e idosos com dificuldades ou não, no campo da educação não formal.

Educador profissional também é a denominação em Luxemburgo, formado pelo Ministério Nacional da Educação, em curso voltado para educação e animação social, orientação socioprofissional e educação para a saúde. Educador especializado é a denominação dada em Portugal aos profissionais que têm como foco o estudo das questões de jovens e adultos em conflito com a lei. Cabe citar, ainda, a experiência do Reino Unido, voltada para a formação do Assistente Social Animador Sociocultural, com eixo na ajuda social a jovens e para a animação sociocultural. No tocante à duração dos referidos cursos, observa-se que há uma pequena variação, em torno de dois a três anos e meio.

Em síntese, pode-se dizer que a educação social e a pedagogia social, no contexto europeu, estão orientadas por valores de justiça, igualdade, fraternidade entre outros; sustentada pelos princípios de uma sociedade democrática, dispondo sua orientação para a ação socioeducativa na perspectiva da integração social. 
Para o cenário latino-americano destaca-se a experiência do Uruguai, ${ }^{5}$ país em que a educação social começou a estruturar-se em meados dos anos 1980 no processo de redemocratização do país e deve ser analisada como resultado da "organização de um coletivo de educadores preocupados com a situação de crianças e jovens vivendo nas ruas e para os quais a escola já não fazia nenhum sentido" (RIBEIRO, 2006, p. 162). Esses educadores enfatizam a educação social como campo da educação que extrapola os conteúdos transmitidos pela escola e como um espaço educativo qualificado para crianças e adolescentes colocados socialmente em situação de risco, aspecto que justifica o acréscimo de "social" à educação, não havendo a negação da função específica da escola. Há, apenas, a preocupação de colocar no centro dos objetivos da educação social as demandas legítimas de parcela da população que vivencia a exclusão - em suas diferentes facetas - no dia a dia.

No Brasil, o processo de estruturação e organização da educação social só recentemente encontrou respaldo teórico e político. Embora Paulo Freire não tenha usado a nomenclatura educação social ou pedagogia social, os pressupostos da educação popular, na concepção transformadora desenvolvida por ele desde a década de 1960, com foco na educação de adultos, aproximam-se dos pressupostos dessa área.

Esse debate vem ganhando expressão no Brasil a partir da segunda década de 1980 e está mais voltado para a área dos direitos da criança e do adolescente, em especial com o Movimento Nacional de Meninos e Meninas de Rua, Pastoral do Menor, Programa Meninos e Meninas de Rua, Projeto Axé, Projeto Travessia, dentre outros. A própria denominação "educador social", no Brasil, emerge desse contexto. Nessa direção, cabe destacar a participação dos educadores sociais no debate sobre a construção de uma política de educação social:

É fato que tem participado deste espaço educadores sociais mais voltados à área de atenção aos direitos das crianças e dos adolescentes, os quais historicamente vivenciaram conjunturas que contribuíram e construíram um novo paradigma nacional [da doutrina de situação irregular para a doutrina da proteção integral], passando pela primeira metade dos anos 80 onde o debate da pedagogia do atendimento teve grande importância e impacto [projetos alternativos], logo somado ao debate da pedagogia

\footnotetext{
${ }^{5}$ Destaca-se que o Uruguai é a sede da Associación Internacional de Educadores Sociales (AIEJI).
} 
do direito [projetos alterativos], fundamentalmente com as contribuições reflexivas do mestre Paulo Freire, o qual propunha ações que, mais que atender os efeitos colaterais do fenômeno da exclusão, sugeria ações que visassem estancar os fatores geradores das mesmas (ENES, 2007, p. 5).

Outros estudos, ainda que incipientes, focalizam a educação social e a pedagogia social, ora como áreas de concentração de uma mesma área de conhecimento, as Ciências da Educação, ora como especialização, ora como aperfeiçoamento. No entanto, segundo Silva (2010), a educação social e a pedagogia social não são sinônimas, não são dicotômicas nem contraditórias, apenas acontecem em espaços e contextos distintos, sendo uma complementar à outra. Ainda de acordo com o autor, três campos de domínio permeiam as discussões sobre a educação social no Brasil: o domínio sociocultural, o domínio sociopedagógico e o domínio sociopolítico, a saber:

O domínio sociocultural tem como áreas de concentração as manifestações do espírito humano expressas por meio do corpo, dos sentidos e do pensamento, tais como as artes, a cultura, a música, a dança e o esporte em suas múltiplas manifestações e modalidades [...]. 0 domínio sociopedagógico tem como áreas de concentração a infância, adolescência, juventude e terceira idade. A intervenção sociopedagogica neste domínio tem como objetivo principal o desenvolvimento de habilidades e competências sociais que permitam às pessoas a ruptura e superação das condições de marginalidade, violência e pobreza que caracterizam sua exclusão social [...]. O domínio sociopolítico tem como áreas de concentração os processos coletivos, sociais e políticos, expressos, por exemplo, na forma de participação, protagonismo, associativismo, cooperativismo, empreendedorismo, geração de renda e gestão social (SILVA, 2010, p. 9-10)

Essa configuração busca atender às questões do cenário apresentado, por meio de uma formação de educadores com domínios até então não incluídos nos cursos de formação. Vale destacar as novas demandas colocadas, também, pela educação formal no novo cenário da educação integral, criando possibilidades de inserção do educador social no âmbito escolar.

A educação social vem se fazendo presente no Brasil em inúmeros eventos que têm fornecido subsídios para a regulamentação da profissão, necessidade reforçada no 
decorrer do século XXI. ${ }^{6}$ Dentre esses eventos, destacam-se as edições do Congresso Internacional de Pedagogia Social (CIPS), realizados na USP; os Colóquios sobre Educação Sociocomunitária realizados pelo Mestrado em Educação Centro Universitário Salesiano de São Paulo (UNISAL) e o Centro de Memória da Universidade Estadual de Campinas (UNICAMP); as Jornadas Brasileiras de Pedagogia Social realizadas em doze cidades brasileiras em 2009; os cinco Encontros Nacionais de Educação Social, realizados a partir de 2001 e promovidos pelos profissionais da área, que se autodenominam educadores sociais, ${ }^{7}$ além dos Encontros Estaduais de Educadores Sociais.

Como destacado por Arroyo (2007), é preciso cuidado com os conceitos, com sua importação ou transposição. Segundo ele, “o problema não é apenas amarrar a educação social, o problema é interrogar a própria concepção de educação social", 8 o que deve ser feita a partir da gramática dos direitos humanos, de conceitos concretos de educação social e conceitos concretos de direitos humanos. A visão liberal e individualista do direito deve dar lugar aos direitos coletivos. A educação social deve seguir a esteira dos direitos difusos e coletivos, como exemplo, direitos infantojuvenis reafirmam os direitos aos tempos da vida, as categorias geracionais como direito coletivo. Ao vincular a educação social na perspectiva da afirmação e efetivação para os direitos humanos, o autor chama a atenção sobre qual o "discurso dos direitos", tendo em vista a recorrente banalização do discurso dos direitos humanos, e pergunta: "Com que concepção de direitos humanos vinculamos a educação social?". ${ }^{9}$ Para Arroyo,

Não significa, porém que vamos saber dar uma educação social de direito, mas também não vamos atrelar a educação social com uma concepção abstrata de direitos, concepção direita de direitos, nem sequer por uma concepção universalista de direitos que na verdade pouco tem de universalista, que é localista de direitos. ${ }^{10}$

\footnotetext{
${ }^{6}$ A construção profissional está em discussão e os concursos públicos para educadores e educadoras sociais, presentes em mais de 100 municípios de 21 estados do país, confirmam o campo de trabalho. A regulamentação da profissão educador social encontra-se nas pautas do Congresso Nacional.

${ }^{7}$ Cf. Encontros Nacionais de Educação Social - ENES (2007).

${ }^{8} \mathrm{Ibid} ., \mathrm{p} .192$.

${ }^{9}$ Ibid., p. 189.

${ }^{10}$ Ibid., 189-190.
} 
Em síntese, a educação social, na perspectiva apontada, trabalha com sujeitos concretos, contextualizados, que tem raça, que tem jeito, tem cidadania.

\section{O Socioeducador}

Neste contexto, situa-se o educador social, profissional que trabalha com população em situação de vulnerabilidade social, cujas ações não são unicamente pedagógicas, mas também culturais, políticas ou ideológicas. O educador social é o profissional que responde sobre ações de caráter socioeducativo, no âmbito de diferentes processos de intervenção.

Com base nessas ideias, o educador social é o profissional que planeja, coordena e operacionaliza atividades tecnológicas e gerenciais no âmbito dos diferentes espaços socioeducativos. $\mathrm{O}$ trato com crianças, jovens e adultos, a visão ampla da educação formal e não formal, a capacidade de comunicação, trabalho em equipe e liderança são características indispensáveis a esse tecnólogo.

Para sua formação, cabe destacar a importância de uma matriz curricular voltada prioritariamente à educação sociocomunitária, atendimento aos segmentos e grupos considerados socialmente vulneráveis, proposição e acompanhamento de programas e projetos sociais, apresenta também uma organização que possibilitará o atendimento às demandas pessoais, sociais, locais e regionais, podendo atuar no campo da educação formal e não formal, em programas e projetos socioeducativos, na mediação de conflitos, em instituições não governamentais, bem como em órgãos públicos.

Assim, educador social, desafiado pela cultura contemporânea, deve estar qualificado para o trabalho com a criança, o adolescente e o idoso, em situação de conflito pessoal e social. Ao mesmo tempo, deve analisar os pressupostos teórico, metodológico e prático da educação social, reconhecendo e valorizando a multiplicidade de ações educativas que estão presentes na vida cotidiana. Ou seja, é preciso formar educadores sociais com foco na construção e desenvolvimento de propostas socioeducativas, garantindo a formação integral e o protagonismo na vida cotidiana, expressos no reconhecimento, na valorização e no exercício dos direitos individuais e coletivos.

Ademais, o educador social, com uma formação de caráter multidimensional, poderá, isoladamente ou integrado a equipes, apresentar-se como um profissional que detém a capacidade de problematizar e enfrentar as questões da sociedade 
contemporânea, fortemente marcada pelos processos de exclusão social. Desse modo, o educador social é o profissional que detecta e analisa os problemas sociais e suas causas, desenvolve atividades de caráter reeducativo (em sentido amplo), contribui para a organização e participa da vida cotidiana e comunitária, anima grupos comunitários e promove atividades socioculturais. Para além desses espaços, o educador social pode atuar no âmbito da escola em processos de formação, informação e orientação da comunidade escolar, ${ }^{11}$ aspecto esse que a própria Lei de Diretrizes e Bases da Educação Nacional (1996) dispõe em seu artigo 10: A educação abrange "processos formativos que se desenvolvem na vida familiar, na convivência humana, no trabalho, nas instituições de ensino e pesquisa, nos movimentos sociais e organização da sociedade civil e nas manifestações culturais" (grifos nossos).

Ainda que a formação acadêmica no campo da educação social esteja aquém das demandas sociais, cabe registrar experiências de formação de socioeducador no nível de pós-graduação, lato sensu e stricto sensu voltados, principalmente, para a atenção aos adolescentes em conflito com a lei. ${ }^{12}$

\section{Considerações Finais}

Os pressupostos da discussão entre a universidade e a socioeducação e seus desdobramentos na formação do socioeducador têm seu apoio na concepção de uma educação social pautada na afirmação e efetivação dos direitos humanos o que significa o seu compromisso na emancipação e autonomia de cada sujeito e sua relação com a sociedade. Elementos orientadores da educação social, fundados no compromisso com as camadas populares, impondo ao educador social práticas educativas pautadas em princípios éticos com a dignidade humana.

Essa temática foi abordada tomando como eixo o cenário socioprodutivo e seus desdobramentos na sociedade contemporânea. Nesse contexto, destacou-se a relação entre educação e sociedade, focalizando o papel da universidade na qualificação do debate

\footnotetext{
${ }^{11}$ Para detalhamento ver: Romans; Petrus; Trilla (2003).

12 Dentre as experiências destacam-se o Mestrado Profissional Adolescente em Conflito com a Lei (stricto sensu) e Adolescente em Conflito com a Lei: práticas profissionais (lato sensu), ambos da Universidade Bandeirante/Anhanguera/São Paulo.
} 
sobre a educação social, as ações socioeducativas e a formação do socioeducador para a atuação nos diferentes espaços e diferentes requerimentos da vida social.

As leituras realizadas mostraram que o debate sobre a temática é insuficiente ainda que as experiências sobre a socioeducação sejam relevantes nos cenários internacional e nacional. A formalização enquanto grupos de estudos, estabelecimento de protocolos para a ação, a produção teórica e a oferta de cursos para a formação do socioeducador mostram, no entanto, um campo a ser efetivamente constituído. Para isso, "vamos ter que aprender outras pedagogias, que aprender outras teorias pedagógicas, aliás, vamos ter que construílas porque não existem" (ARROYO, 2007, p. 191).

\section{Referências}

ANASTASIOU, L. das G. Metodologia de ensino na universidade brasileira. In: CASTANHO, S.; CASTANHO, M. E. (Org.). Temas e Textos em Metodologia do Ensino Superior. Campinas: Papirus, 2001.

ARROYO, I. G. Educação social na perspectiva da efei8vação dos direitos humanos: educação e direitos humanos. In: Encontros Nacionais de Educação Social (ENES). Elo Instituto de Promoção e Defesa da Cidadania, Belo Horizonte: Dinâmica Gráfica e Editora, 2007.

BAPTISTA, I. N. Educação social: uma outra história é possível? In: Encontros Nacionais de Educação Social (ENES). Elo Instituto de Promoção e Defesa da Cidadania, Belo Horizonte: Dinâmica Gráfica e Editora, 2007.

CUNHA, L. A. A universidade temporã: o ensino superior da colônia à era Vargas. 3. ed. São Paulo: UNESP, 2007.

CURY, C. R. J. Graduação/pós-graduação: a busca de uma relação virtuosa. Educação \& Sociedade. CEDES, Campinas, v. 25, n. 88, p. 777-93, Especial, out. 2004 . Políticas inclusivas e compensatórias na educação básica. Cadernos de Pesquisa (35), n. 124, SP: FCC, 2005. jan./abr., p. 11-32.

ENES - Encontros Nacionais de Educação Social. Anais... Belo Horizonte. ELO - Instituto de Promoção e Defesa da Cidadania. Dinâmica Gráfica e Editora, julho de 2007.

ESPINHEIRA, G. Conflito e convivência na cultura da violência: Periferia e pobreza. In: .; CARVALHO, A. M. de. Desenvolvimento Comunitário Bairro de Plataforma.

Salvador: Universidade Federal da Bahia. Centro de Recursos Humanos, 2003, p. 67-76.

FÁVERO, M. de L. A universidade no Brasil. Revista Brasileira de Educação. São Paulo, n.10, 1999. jan./abr. p. 2. 
MACHADO, E. M. Pedagogia social no Brasil: políticas, teorias e práticas em construção. Curitiba. In: IX Congresso Nacional de Educação, out./2009, PUC-PR.

MOISEICHYK, A. E.; BIAZUS, C. A. O papel da universidade diante do contexto atual: uma questão de responsabilidade social. In: II Coloquio Internacional Gestión Universitaria n América del Sur. Universidade Federal de Santa Catarina e Universidad Nacional de Mar Del Plata. Mar Del Plata, Argentina. dez./2011.

RIBEIRO, M. Exclusão e educação social: conceitos em superfície e fundo. Educação \& Sociedade, Campinas, v. 27, n. 94, p. 155-178, jan./abr. 2006

ROMANS, M.; PETRUS, A.; TRILLA, J. Profissão: educador social. Porto Alegre: Artmed, 2003.

SGUISSARDI, V. A universidade neoprofissional, heterônoma e competitiva. In: FÁVERO, M. de L.; MANCEBO, D. (Org.). Universidade - Políticas e avaliação docente. São Paulo: Cortez, 2004.

SILVA, R. da. A experiência internacional em Educação Social e sua regulamentação como profissão no Brasil. In: CIBS - Conselho Internacional de Bem-Estar Social. 2004.

Disponível em <http://www.cibs.cbciss.org/relatos.html.>. Acesso em 13 de setembro de 2010.

SOARES, L. E. Justiça: pensando alto sobre violência, crime e castigo. Rio de Janeiro: Nova Fronteiram, 2011.

TRINDADE, H. Universidade em perspectiva. Sociedade, conhecimento e poder. Trabalho apresentado na 21a Reunião Anual da ANPED, no GT: Política de Educação Superior. Brasil, RJ, Caxambu, set./1998. Disponível em: <htpp://www.anped.org.br>. Acesso em 28 de agosto de 2008.

WAISELFISZ, J. J. Mapa da Violência 2012 - Crianças e adolescentes do Brasil. Folha de São Paulo. Caderno C5, 18 de jul./2012. 